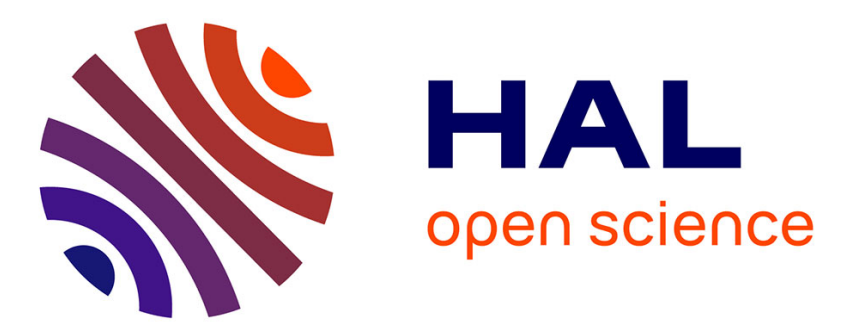

\title{
Observation of new X-ray diffuse scattering features in FeNb3Se 10
}

\author{
R. Moret, J.P. Pouget, A. Meerschaut, L. Guemas
}

\section{To cite this version:}

R. Moret, J.P. Pouget, A. Meerschaut, L. Guemas. Observation of new X-ray diffuse scattering features in FeNb3Se 10. Journal de Physique Lettres, 1983, 44 (2), pp.93-97. 10.1051/jphyslet:0198300440209300 . jpa-00232148

\section{HAL Id: jpa-00232148 https://hal.science/jpa-00232148}

Submitted on 1 Jan 1983

HAL is a multi-disciplinary open access archive for the deposit and dissemination of scientific research documents, whether they are published or not. The documents may come from teaching and research institutions in France or abroad, or from public or private research centers.
L'archive ouverte pluridisciplinaire HAL, est destinée au dépôt et à la diffusion de documents scientifiques de niveau recherche, publiés ou non, émanant des établissements d'enseignement et de recherche français ou étrangers, des laboratoires publics ou privés. 
Classification

Physics Abstracts

$61.50 \mathrm{~K}-71.30-72.15 \mathrm{~N}$

\title{
Observation of new $X$-ray diffuse scattering features in $\mathrm{FeNb}_{3} \mathrm{Se}_{10}$
}

\author{
R. Moret, J. P. Pouget \\ Laboratoire de Physique des Solides, bât. $510\left(^{*}\right)$ and LURE, bât. 209 C, \\ Université Paris-Sud, 91405 Orsay, France
}

\section{A. Meerschaut and L. Guemas}

Laboratoire de Physico-chimie des Solides (*), Université de Nantes, 44072 Nantes, France

(Reçu le 13 septembre 1982, révisé le 23 novembre, accepté le 29 novembre 1982)

\begin{abstract}
Résumé. - Nous présentons les résultats d'une étude par diffusion diffuse des rayons $\mathrm{X}$ de $\mathrm{FeNb}_{3} \mathrm{Se}_{10}$. Le rayonnement synchrotron a été utilisé conjointement avec les sources standard. Des lignes diffuses de vecteur d'onde $(0,5,0,33, l)$ ont été mises en évidence. Leur intensité augmente quand la température décroît, mais elles restent diffuses, quoique modulées, jusqu'à $20 \mathrm{~K}$. Ces résultats devraient initier de nouvelles études structurales pour ce composé.
\end{abstract}

\begin{abstract}
We present the results of an X-ray diffuse scattering study of $\mathrm{FeNb}_{3} \mathrm{Se}_{10}$ using both standard and synchrotron radiations. New diffuse scattering features in the form of rods with reduced wave vectors $(0.5,0.33, l)$ have been observed. Their intensity grows as the temperature is reduced but the diffuse character is preserved down to $20 \mathrm{~K}$ though intensity modulations are present. These results call for a careful structural re-investigation of this compound.
\end{abstract}

The compound $\mathrm{FeNb}_{3} \mathrm{Se}_{10}$ exhibits intringuing transport and structural properties. Most remarkable is the metal-insulator transition at $T_{\mathrm{MI}} \simeq 140 \mathrm{~K}$, with an increase of resistivity by about nine orders of magnitude down to $3 \mathrm{~K}$ [1]. An incommensurate structural distortion develops in the same temperature range and has been attributed to the onset of a charge-density wave [1]. The structure consists of two types of chains running parallel to the $b$-direction (two fold axis) $[2,3]$. One is built from $\left[\mathrm{NbSe}_{6}\right]$ trigonal prisms sharing triangular faces and is very similar to one of the three chains present in the parent $\mathrm{NbSe}_{3}$ compound. The other is composed of edge-sharing $\left[(\mathrm{Fe}, \mathrm{Nb}) \mathrm{Se}_{6}\right]$ octahedra forming a double chain with disordered metal atoms. A correlation between the metal-insulator transition and the occurrence of the charge-density wave has been proposed recently [4]. The authors suggest that the charge density wave driven reduction in conduction electron density allows the observation of an Anderson type of metalinsulator transition (electron localization being due to random potentials created by disorder among the $\mathrm{Fe}-\mathrm{Nb}$ atoms). More work is needed to confirm and gain a deeper understanding of this behaviour.

(*) Laboratoires associés au C.N.R.S. 
In this paper we re-investigate the low-temperature structural data using X-ray diffuse scattering techniques. Besides the previously reported incommensurate satellites [1] a new type of diffuse scattering is observed. It takes the form of diffuse rods in reciprocal space, probably modulated in intensity. Being weak but already detectable at room temperature it grows as the temperature is decreased. The intensity of this new diffuse scattering is generally higher than that of the known satellites. The implications of these findings are briefly discussed.

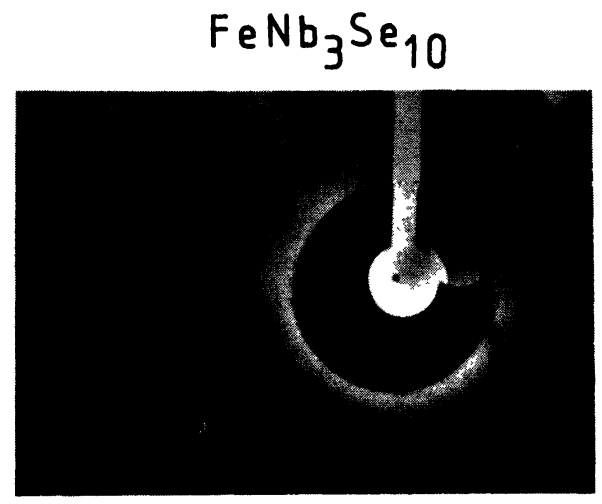

a) $T=295 \mathrm{~K}$

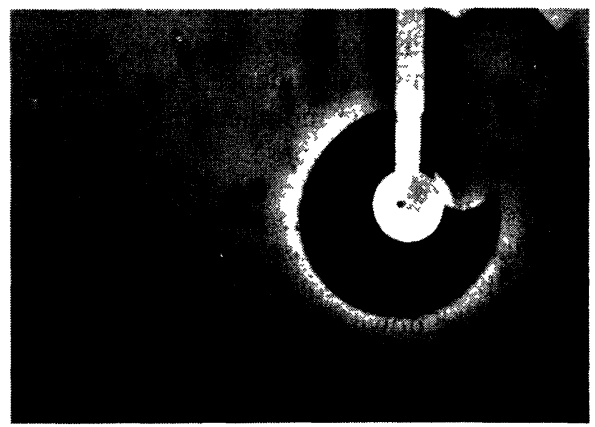

b) $T=100 \mathrm{~K}$

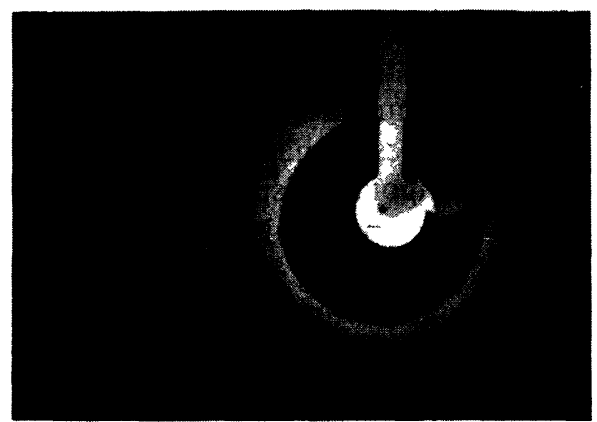

c) $T=20 \mathrm{~K}$

Fig. 1. - X-ray diffuse scattering photographs of $\mathrm{FeNb}_{3} \mathrm{Se}_{10}$ at room temperature, $100 \mathrm{~K}$ and $20 \mathrm{~K}$. The b axis is horizontal and tilted by $71^{\circ}$ from the direct beam. The [101] direction in real space is vertical. These photographs were taken with synchrotron radiation monochromated by a Ge crystal $(\lambda=1.13 \AA)$. 
Needle-shaped crystals of $\mathrm{FeNb}_{3} \mathrm{Se}_{10}$ were prepared as described earlier [2]. They are generally larger and exhibit a better crystallinity than crystals of the parent $\mathrm{NbSe}_{3}$ compound. X-ray diffuse scattering photographs were made with stationary single-crystals and monochromatic radiation. Both $\mathrm{CuK} \alpha$ radiation (graphite monochromator) and synchrotron radiation [5] (germanium monochromator) were used. Apart from its high intensity the synchrotron source has the advantage of allowing a reduction of the fluorescence scattering by choosing a proper wavelength.

Several crystals from different batches have been examined and they exhibited identical behaviours. Figure 1 shows a typical set of diffuse scattering photographs at different temperatures. The crystal is oriented with $\mathbf{b}^{*}$ (collinear with b, chain axis) horizontal and the [101] direction of the direct lattice is vertical. Analysis and indexing of such photographs were made easier by the use of a computer program. Figure 2 shows a schematic drawing where the main features of figure 1 are reproduced and indexed. The following description will be based on the correspondence between these two figures. Apart from strong spots coming from reciprocal lattice points which satisfy Bragg condition, figure 1 shows a number of diffuse spots whose intensity increases as $T$ is reduced. These later spots can be classified in two categories, referred as 1 and 2 and symbolized by solid triangles and dots, respectively, in figure 2 .

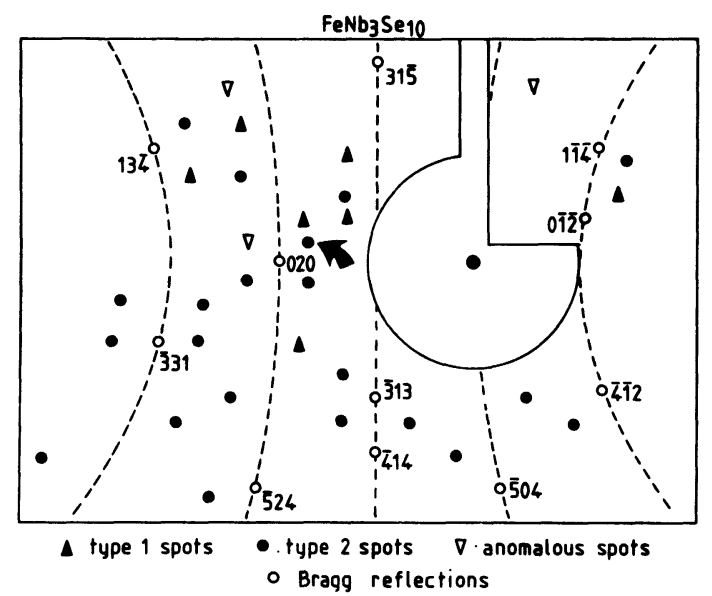

Fig. 2. - Schematic pattern illustrating the diffuse spots of figures $1 b, c$. The dotted lines represent the traces of the reciprocal planes $h 3 l, h 2 l, h 1 l, h 0 l$ and $h \bar{l} l$ (left to right). Some Bragg reflections are indexed. The arrow points to the diffuse spots used for densitometric measurement of the FWHM.

Spots of type 1 correspond to reduced components along $b^{*}$ which are slightly larger than $1 / 4$. Their reduced wave vectors can be indexed as $\mathbf{q}_{1}=(0,0.27 \pm 0.01,0)$. This is in good agreement with the value determined by Hillenius, Coleman, Fleming and Cava (HCFC) [1] in their study of the charge-density wave formation. Accordingly we conclude that satellites of type 1 are those already observed. HCFC reported a weak temperature dependence of the $b^{*}$ component $(0.27$ near $140 \mathrm{~K}$ and 0.258 near $6 \mathrm{~K}$ ) which seems to be confirmed by a careful analysis of photographs such as figure 1, although the poor accuracy of the indexation does not allow a reliable estimation of this variation to be made. The peak intensity of these satellite builds up gradually as $T$ is lowered (see Fig. 3) while they remain several times broader than main Bragg reflections even at $20 \mathrm{~K}$. The intensity variation is comparable to that reported by HCFC although even more rounding is observed. The transition is very smooth and broad around $T \simeq 140 \mathrm{~K}$.

However type 1 satellites are not the only scattering features that develop at low temperature. They are actually outnumbered by type 2 spots as clearly seen from figures 1 and 2 . The reduced $b^{*}$ component of these new spots is estimated to be $1 / 3$ (with an accuracy of 0.01 ) with no detectable 


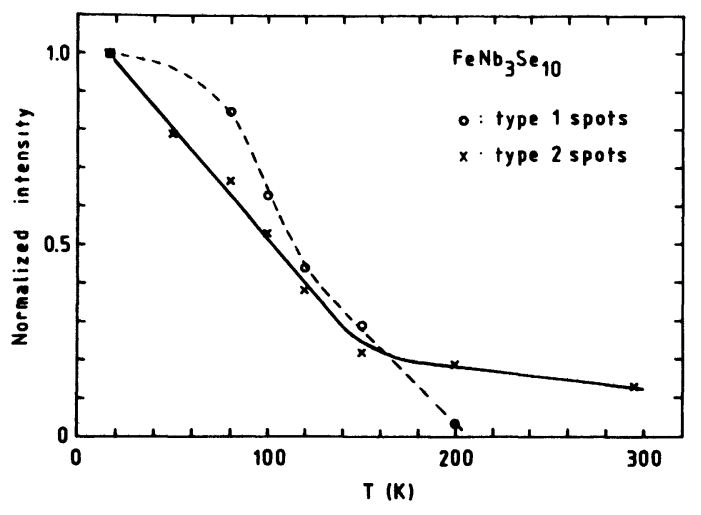

Fig. 3. - Normalized peak intensity of the 2 types of diffuse scattering as a function of temperature. The lines are guides to the eye.

temperature dependence. Derivation of the other wave vector components is not straightforward but they can be estimated from comparison with computed diffraction patterns. Indexation yields about 0.5 for the $a^{*}$ component but the $c^{*}$ coordinates vary from spot to spot thus implying that we are dealing with intensity modulated segments running along $c^{*}$ or at least diffuse reflections very much extented in this direction. This is also"supported by the observation of diffuse streaks when these rods are close to be tangent to the Ewald sphere. Therefore we are led to wave vectors of the form $\mathbf{q}_{2}=(0.5,0.33, l), l$ being variable. Such a geometry in reciprocal space also explains the large number of type 2 spots visible on figure 1 since the diffraction condition is more easily fulfilled for diffuse lines than for satellites (even though the type 1 satellites are anisotropic [1]).

The intensity of type 2 diffuse scattering is generally higher than that of type 1 , thus probably indicating larger structural modifications. Since what we observe are the intersections of modulated diffuse segments with the Ewald sphere it is hazardous at first sight to extract the temperature dependence of the type 2 diffuse intensity from microdensitometer scans of the photographs. However there is an overall intensity increase as $T$ is reduced even though some diffuse scattering condensation takes place simultaneously. A typical peak intensity variation with $T$ is shown in figure 3. Starting from room temperature the intensity increases slowly down to about $150 \mathrm{~K}$ then much faster and almost linearly. The linear part extrapolates to about $190 \mathrm{~K}$ but, so far, no anomaly in the transport properties has been found in this region. The width of the type 2 scattering along $\mathbf{b}^{*}$ is comparable to that of type 1 and at least 6 times broader than the main Bragg reflections. For example microdensitometer measurement of the width of a typical spot (indicated by an arrow on Fig. 2) gives a FWHM of $0.11 \AA^{-1}\left(\mathbf{b} . \mathbf{b}^{*}=2 \pi\right)$ corresponding to a correlation length of about $22 \AA$ in chain direction at $20 \mathrm{~K}$. It is remarkable that no significant sharpening of the diffuse scattering is observed between about $150 \mathrm{~K}$ and $20 \mathrm{~K}$.

Although most of the spots (other than those of type 1 ) can be indexed as $(0.5,0.33, l)$, a few ones, indicated by open triangles in figure 2 , do not correspond to this indexation. Their reduced $b^{*}$ component is equal or close to $1 / 3$ but owing to the relatively low accuracy of our method it is not possible to obtain consistent values for the other components. These " anomalous " spots should be studied by diffractometry.

Associating our results with those of the HCFC study it is clear that the existence of the type 2 scattering features leads to reconsider the behaviour of $\mathrm{FeNb}_{3} \mathrm{Se}_{10}$. The current model proposed by these authors on the basis of structural similarities with $\mathrm{NbSe}_{3}$ is that the type 1 incommensurable satellites come from the onset of a charge-density wave affecting the trigonal prismatic $\mathrm{NbSe}_{6}$ chains. If we retain this model, then it is tempting to associate the type 2 scattering features 
with distortions of the $(\mathrm{Fe}, \mathrm{Nb}) \mathrm{Se}_{6}$ octahedral double chains. The $\mathbf{q}_{2}$ values of $(0.5,0.33, l)$ imply that these distortions double and triple the lattice periodicities in the $\mathbf{a}$ and $\mathbf{b}$ direction, respectively. On the other hand the rod-like geometry of the diffuse scattering indicates that $(a, b)$ layers of octahedral chains experience little correlation of the distortions from layer to layer.

The nature of the distortions in the $(a, b)$ planes is not easily identified from the structure geometry and the possible bondings since 2-D correlations rather seem to develop in $(b, c)$ planes. Structure refinements agreed that the $\mathrm{Fe}$ and $\mathrm{Nb}$ atoms are randomly distributed among the octahedral sites. However there is some uncertainty about the $\mathrm{FeNb}_{3} \mathrm{Se}_{10}$ composition which implies equal amounts of $\mathrm{Fe}$ and $\mathrm{Nb}$ in the octahedra. A very recent study [6] argues that the actual composition is $\mathrm{Fe}_{1+x} \mathrm{Nb}_{3-x} \mathrm{Se}_{10}(0.25<x<0.40)$, so that $\mathrm{FeNb}_{3} \mathrm{Se}_{10}(x=0)$ would not exist. One can envisage that the distortions are linked to some kind of partial order (overlooked by standard structure analysis) among the $\mathrm{Fe}$ and $\mathrm{Nb}$ atoms in the octahedral chains.

Accordingly the $\mathrm{Fe}_{1+{ }_{x}} \mathrm{Nb}_{3-x} \mathrm{Se}_{10}$ formula allows to propose a tentative explanation for the $0.33 \mathbf{b}^{*}$ component of $\mathbf{q}_{2}$. Taking $x$ close to $1 / 3$ we get $\left[\mathrm{Fe}_{1.33} \mathrm{Nb}_{0.67}\right]_{\text {oct. }}\left[\mathrm{Nb}_{2}\right]_{\text {prism }} \mathrm{Se}_{10}$ so that the occupancy ratios are $1 / 3(\mathrm{Nb})$ and $2 / 3(\mathrm{Fe})$ in the octahedra. Therefore, order among these atoms could generate a triple periodicity in the $b$-direction.

The question of stoichiometry could also intervene in the differences between our results and the HCFC study. Further work should be devoted to this question and to a more quantitative X-ray characterization using diffractometry.

Acknowledgments. - We wish to thank S. Megtert for help with the synchrotron experiments.

\section{References}

[1] Hillenius, S. J., Coleman, R. V., Fleming, R. M. and Cava, R. J., Phys. Rev. B 23 (1981) 1567.

[2] Meerschaut, A., Gressier, P., Guemas, L. and RouXel, J., Mat. Res. Bull. 16 (1981) 1035.

[3] Cava, R. J., Himes, V. L., Mighell, A. D. and Roth, R. S., Phys. Rev. B 24 (1981) 3634.

[4] Hillenius, S. J. and Coleman, R. V., Phys. Rev. B 25 (1982) 2191.

[5] Synchrotron experiments were conducted at LURE, Orsay, on station D16. Typical operating conditions of the storage ring were $1.72 \mathrm{GeV}$ and $310 \mathrm{~mA}$.

[6] Whangbo, M. M., Cava, R. J., Di Salvo, F. J. and Fleming, R. M., Solid State Commun. 43 (1982) 277.

Commission paritaire $N^{\circ} 59.024$

(C) Les Editions de Physique 1982 Directrice de la Publication : Jeanne BERGER 